\title{
Introduction
}

\section{Qualitative Longitudinal Research for Social Policy - Where Are We Now?}

\author{
Ruth Patrick*, Morag Treanor** and Aniela Wenham*** \\ *Department of Social Policy and Social Work, University of York, York, UK \\ E-mail: ruth.patrick@york.ac.uk \\ **Institute for Social Policy, Housing, Equalities Research (I-SPHERE), Heriot-Watt University, \\ Edinburgh, UK \\ E-mail: m.treanor@hw.ac.uk
}

***Department of Social Policy and Social Work, University of York, York, UK

E-mail: aniela.wenham@york.ac.uk

\section{The pandemic and time: a never-ending present}

'The relationship to time is at the root of what makes us human' (Adam, 2006: 121)

Qualitative longitudinal researchers are principally occupied with researching time; with tracking the presence and absence of change over time; and with exploring how people remake and reinterpret their past, present and future lives and selves in different ways, and at different times (Holland et al., 2006; Thomson and McLeod, 2015; Neale, 2019; Hollstein, 2021). As such, all three of us, as qualitative longitudinal researchers, felt we had at least some understanding of the vagaries and complexities of time. However, as we moved into 2020, the global pandemic of COVID19 forced us to re-evaluate our own temporal rhythms. The last twelve months have shown us all - brutally at moments - the ways in which time can challenge and confuse us; with seemingly endless national lockdowns that leave us suspended in often difficult presents; and with projections of the future taking on a particularly fragile and precious quality. For many of us, the present has never felt so uncertain, as we variously yearn and wait for the return to school, to human contact, and to a life that feels more like our pasts. A past, which can, at times, feel so very far away. In tandem to this, there is a merited focus on the future; with debate over how we might 'build back better' to create a 'new normal', discussions which themselves draw upon contested and varied depictions of the past.

The pandemic has also served as an exemplar of Barbara Adam's (2006) argument that chronological or clock time is often not appropriate for understanding the traversing and experiencing of the temporal (Adam, 1990, 2006). Rather than thinking of time as fixed to the regularities of the clock and the calendar, and following the work of Adam $(1990,2006)$ and of Neale (see this issue), it is better to explore time as itself fluid: as an 'experiential and socially constructed entity' (Neale in this themed section), time inheres 
in events, practices and processes. The pandemic and our experiences of time (and reworking of time across it) have shown the extent to which people do not experience time in a fixed, constant and linear way. As Neale puts it, drawing on the work of Adam (1990, 2006):

'Past and future, for example, are no longer separate states that progress chronologically, in a linear direction; they are processes that flow into one another, suggesting that our understandings of our past are no more fixed than the future... In all their complexity and flux, social practices and events do not occur in time, they constitute time. Time becomes our creation' (Neale, 2019: 25, emphasis in original).

This conceptualisation of the plurality of times, of the inherent fluidity of time, and its scope to be reworked, is exemplified by our collective and individual experiences of living through the pandemic. A pandemic which has been truly global in its reach and impact, and which has fundamentally disrupted everyday lives, and societal and economic relations.

This themed section - with its focus on qualitative longitudinal research's applicability for social policy - was conceived before the pandemic, emerging from discussion at a workshop at the 2018 Social Policy Association's Annual Conference at the University of York. The workshop session, which focused on exploring the craft of qualitative longitudinal research, reinforced to us all the value in creating a space to explore QLR's very specific value for social policy research.

The development of the articles found in this themed section, and our own contribution, took place at the height of the pandemic, while we have all variously balanced pressures of working (and occasionally writing) with parenting and coping with the health fallout from the pandemic. We have all faced an incredibly busy present - across these past twelve months - and a present that has reinforced to each of us the incredible richness and importance of a detailed analysis of the temporal. This has drawn attention to the shifting roles the past, present and future can perform in our own lives, and in the narratives we construct to seek to understand them and their relationship to wider social processes (Saldana, 2003; Thomson and Holland, 2003).

\section{Why explore QLR's relevance for social policy?}

While we have struggled with the pressures we have faced, we have also found motivation in our renewed belief in the value of exploring and understanding time, in tandem with a social policy analysis of policy changes and developments. That is the central motivation behind this themed section, and the collection of articles found within it, each of which, albeit in very different ways, contribute to developing our understanding of the very real and specific benefits of QLR for social policy research.

Our starting point for this themed section is very much an acknowledgement of the debt we owe to the 2007 themed section in the same journal on qualitative longitudinal research for social policy, which was edited by Anne Corden and Jane Millar, and which also started life at a workshop, in this case one hosted by the Social Policy Association in 2005. The subsequent groundbreaking collection of articles made a compelling case for the value and importance of QLR at a time when its relevance to social policy research was only beginning to attract widespread recognition (Corden and Millar, 2007a, 2007b). 
It is no doubt in some part due to this themed section itself that the intervening years have seen a considerable growth in the methodology within social policy, with high profile and impactful research rooted in a privileging of the temporal and in an exploration of the presence (but also critically the absence) of change over time (see, for example, Dwyer, 2018; Dwyer, 2020; Millar and Ridge, 2020; Tarrant et al., 2020; Wright and Dwyer, 2020; Hill and Webber, 2021; Scullion and Curchin, 2021). There has been a growing awareness of the potential inherent to QLR, something which is acknowledged by Bettina Hollstein (2021), in an introduction to another themed section exploring the possibilities inherent with QLR, here expanding the focus to include lifecourse and health research:

Following individuals over time and grasping rich and fine-grained data about their practices, perceptions and perspectives is an exciting and engaging endeavour that promises important findings concerning substantive issues in life course research, social policy, and health research (2021, unpaginated).

Where the 2007 articles by Anne Corden and Jane Millar within their special edition (Corden and Millar, 2007a, 2007b) were especially persuasive was in making the case for the very specific relevance of QLR for policy interventions that are targeted at changing behaviour - for example, through conditionality or broader processes of welfare reform (most recently, cuts and retrenchment). The invitation to use QLR to better understand experiences and thus the effectiveness of such interventions was taken up by academics both in the UK and internationally and has helped secure the profile of the methodology within social policy. In our own research, we have used the method in this way; teasing out and exploring the consequences of welfare conditionality and welfare reform (Patrick, 2017), interventions targeted at young parents (Wenham, 2016) and policies targeted at priority groups under the Child Poverty (Scotland) Act 2017 (Treanor, 2018). What these research experiences have demonstrated to each of us is the value of the method, but also of the need for continued and broader exploration of its particular applicability and strengths - plus challenges (see, for example, Wright and Patrick, 2019; Dwyer and Patrick, 2021).

In essence, that is what motivates this themed section, which we hope will help the next generation of QLR researchers to think through and explore how best to integrate the method into their own work.

\section{Tracking change and continuity over time - from causality to ethics}

Our themed section starts with a contribution from Professor Jane Millar, who reflects upon over fifteen years of repeat interviews with a cohort of lone mothers. Millar sets out the extent to which - over the longer duree of her study - what was perhaps most notable among the women she was interviewing comprised broader processes of continuity rather than change. While many of the mothers experienced short-term changes, often frequently, their lives were marked by a continuity in terms of the persistent experience of financial and economic hardship and relative insecurity. Despite movements in and out of work, and children growing up and leaving home, this often appeared as a constant in their lives. This conclusion is important in terms of understanding how the broader policy context intersects with lived experiences, but also in terms of our engagement with the methodology for two reasons. First, it shows the real importance of tracking continuity as well as 
change: especially, against a policy context which is so firmly orientated towards, and justified on the basis of, stimulating change. Second, it shows the benefit in research that follows individuals over a longer timeframe; and there are linked implications for funders and for institutional processes (particularly around precarity and fixed-term employment) which can make achieving such a long period of repeat engagement difficult. Here, it is important to note that Millar and Ridge have had to secure different funding for successive waves of their interviews, and this brings inevitable methodological challenges, especially as they relate to sustaining a sample over time.

One thing that undoubtedly characterised all of the research, which is reflected upon in this themed section, is a desire to engage with policy, and to try, through developing new research knowledge, to improve policy and practice over time. This underpinning ambition is explored in Bren Neale's article, in which she draws out how far, and to what degree, QLR can be used to illuminate causal processes and so - in policy terms - to help us understand 'what works' for policy and practice (see Neale in this themed section). Neale's article sets out the ways in which QLR enables us to follow reality in all its windings', and - by so doing - adopt a more fluid form of enquiry that can facilitate explorations of causal processes 'on the ground'. As Neale puts it in her article:

QL Research, with its flexibility, responsiveness, and its grounded, processual nature, can tease out and trace the multiple causal threads that operate through the stream of time.'

In concluding, Neale sets out a prototype for what she describes as a QL impact design, which would be directly orientated to working with policymakers within a research project as part of an effort to explore and learn from causal processes, and to directly influence the policymaking process. This is a significant contribution, and one which provides a means of embedding an orientation towards developing and working with policymakers over time into the core of a research design, which is itself then firmly orientated towards policy engagement and ultimately impact.

Scullion and colleagues have a long track record of demonstrating the possibilities for impact to arise directly from QL inquiry - both through their involvement in the large-scale and ambitious welfare conditionality research project (see Dwyer, 2018) but also in repeat interviews, which explore veterans' interactions with the social security system, and which make up the focus of their contribution to this themed section (see also Scullion and Curchin, 2021). Interestingly, and following Neale's contribution, Scullion et al. place emphasis on the extent to which they feel that their methodological design - the QLR approach - was itself essential to securing meaningful impact and policy change. They illustrate the ways in which their relationships with policymakers evolved over the course of the research; moving from 'initial reluctance to one of significant engagement with the research team, supporting real policy change'. We often hear how research relationships improve and deepen over the course of a QLR study: for example, enabling (as documented in Millar's piece in this themed section) greater trust between research participant and researcher, and thus the disclosure of fuller details of individual lives at later interviews. We hear less about the same possibilities for deepening trust and stronger relationships between research teams and other stakeholders; and Scullion et al.'s article demonstrates the importance of attending to and evidencing the possibilities that are also contained in this domain (something that we also draw out in our own contribution to this 
themed section, the State of the Art article entitled 'Qualitative Longitudinal Research: from monochrome to technicolour').

Bren Neale's article also sets out the importance and potential within QLR for fluidity, as regards to the process of enquiry, the conceptualisation of time, and the subsequent understanding of causality that emerges from research efforts that follow individuals through time. This is further illustrated in the themed section's contribution from Davidson, Nugent and Johnsen, which documents four individuals' 'journeys' through homelessness services. Their accounts show the fluidity and complexity of these journeys, with Davidson et al. arguing further that they show the extent to which effective policy interventions require time intensity and involvement, which in many ways mirror what is required by those undertaking qualitative longitudinal research. Davidson et al. draw out the additional demands that QLR makes on researchers. These are intrinsic to the method, rooted in the fluidity (which less positively could be described as the uncertainty, and changeability) of the QLR research process (see also Holland et al., 2006; Thomson and McLeod, 2015; Neale, 2019). Drawing a parallel with long-term supportive interventions for homeless populations, they argue:

'Method, policy and practice mirror each other in their requirement and interest in time, relationships and ethics. This mirroring highlights the value of methods, policies and practices that focus on listening, hearing and 'spending time with'

(see Davidson et al. in this themed section).

At root, the recognition of the time that QLR takes is a vital one, and one that we need to continue to persuade funders and colleagues is best construed as a worthwhile and valuable investment (as evidenced in all of the contributions within this themed section). In our own article, we also seek to make this case, while exploring in some detail the ethical plane for QLR inquiry; and the extent to which ethical challenges are inevitably magnified by the research's more intensive involvement and engagement in individual lives (McLeod and Thomson, 2009). We additionally, and in common with each of these contributions, extract the possibilities for richer and more effective policymaking engagement, drawing on examples from our own research experiences. Fourteen years ago, Anne Corden and Jane Millar (2007a, 2007b) set out the potential for QLR to enrich social policy research and practice. In the intervening years, this has been demonstrated by a rich and growing body of research evidence. Our hope is that this themed section continues to build and extend the case, while also suggesting rich new avenues of enquiry.

\section{Concluding thoughts}

At the beginning of this introduction, we emphasised how the conditions of the pandemic have both shaped the development of this themed section but have also reinforced to us the complexity of time as a process and experience and the linked importance of honing our research lens onto the temporal (see Adam, 1990, 2006; Neale in this issue). With the global pandemic disrupting our temporal processes, it has facilitated a greater appreciation of the complex relationship between the past, present and future. Whilst the past may always hold a sense of being absent, its features endure and hold meaning in the present, as well as the many, varied ways in which we might envisage the future. 
In concluding, we would like to thank all those who made the task of completing a themed section during a pandemic possible; our fantastic contributors; the reviewers who kindly gave their time to the articles; and the editorial team at the journal who were understanding and patient about each missed deadline. We would also like to acknowledge and thank our families; who have supported us with the time-intensive and often stressful juggling of parenting, paid work and sometimes ill-health across this pandemic, and who we know will continue to support us into what we hope will be a better, muchlonged-for future.

\section{References}

Adam, B. (1990) Time and Social Theory, Cambridge: Polity.

Adam, B. (2006) 'Time', Theory, Culture and Society, 23, 2-3, 119-38.

Corden, A. and Millar, J. (2007a) 'Qualitative longitudinal research for social policy - introduction to themed section', Social Policy and Society, 6, 4, 529-32.

Corden, A. and Millar, J. (2007b) 'Time and change: a review of the qualitative longitudinal research literature for social policy', Social Policy and Society, 6, 4, 583-92.

Dwyer, P. (2018) Final Findings, Welfare Conditionality: Sanctions, Support and Behaviour Change, York, University of York, http://www.welfareconditionality.ac.uk/wp-content/uploads/2018/05/40414_ Overview-HR4.pdf [accessed 07.04.2021].

Dwyer, P. (2020) 'Questions of conduct and social justice: the ethics of welfare conditionality within UK social security', in A. Eleveld, T. Kampen and J. Arts (eds.), 'Welfare to Work in Contemporary European Welfare States: Legal, Sociological and Philosophical Perspectives on Justice and Domination', Bristol: Policy Press, 198-210.

Dwyer, P. and Patrick, R. (2021) 'Little and large: methodological reflections from two qualitative longitudinal policy studies on welfare conditionality', Longitudinal and Life Course Studies, 12, 1, $63-81$.

Hill, K. and Webber, R. (2021) Seeking an Anchor in an Unstable World: Experiences of Low-Income Families Over Time, York: Joseph Rowntree Foundation, https://www.jrf.org.uk/report/seekinganchor-unstable-world-experiences-low-income-families-over-time [accessed 07.04.2021].

Holland, J., Thomson, R. and Henderson, S. (2006) Qualitative Longitudinal Research: A Discussion Paper, Working paper no. 21, London South Bank University.

Hollstein, B. (2021) 'Promises and pitfalls of qualitative longitudinal research', Longitudinal and Life Course Studies, 12, 1, 7-17.

McLeod, J. and Thomson, R. (2009) Researching Social Change, London, Sage.

Millar, J. and Ridge, T. (2020) 'No margin for error: fifteen years in the working lives of lone mothers and their children', Journal of Social Policy, 49, 1, 1-17.

Neale, B. (2019) What is Qualitative Longitudinal Research, London: Bloomsbury Academic.

Patrick, R. (2017) For Whose Benefit? The Everyday Realities of Welfare Reform, Bristol: Policy Press.

Saldana, J. (2003) Longitudinal Qualitative Research: Analyzing Change through Time, Walnut Creek, Altamira Press.

Scullion, L. and Curchin, K. (2021) 'Examining veterans' interactions with the UK social security system through a trauma-informed lens', Journal of Social Policy, doi: 10.1017/S0047279420000719.

Tarrant, A., Way, L. and Laidlow, L. (2020) 'Negotiating 'earning' and 'caring' through the COVID-19 crisis: change and continuities in the parenting and employment trajectories of young fathers', https://fyff. blogs.lincoln.ac.uk/2020/12/16/our-first-two-briefing-papers-in-the-covid-19-and-young-fathersseries-are-now-available/ [accessed 07.04.2021].

Thomson, R. and Holland, J. (2003) 'Hindsight, foresight and insight: the challenges of qualitative longitudinal research', International Journal of Social Research Methodology, 6, 3, 233-44. 
Thomson, R. and McLeod, J. (2015) 'New frontiers in qualitative longitudinal research: an agenda for research', International Journal of Social Research Methodology, 18, 3, 243-50.

Treanor, M. C. (2018) 'Falling through the cracks: the cost of the school day for families living in in-work and out-of-work poverty' Scottish Affairs, 27, 4, 486-511.

Wenham, A. (2016) "I know I'm a good mum - no one can tell me different." Young mothers negotiating a stigmatised identity through time', Families, Relationships and Societies, 5, 1, 127-44.

Wright, S. and Dwyer, P. (2020) 'In-work universal credit: claimant experiences of conditionality mismatches and counterproductive benefit sanctions', Journal of Social Policy, doi: 10.1017/ S0047279420000562.

Wright, S. and Patrick, R. (2019) 'Welfare conditionality in lived experience: aggregating qualitative longitudinal research', Social Policy and Society, 18, 4, 1-17. 